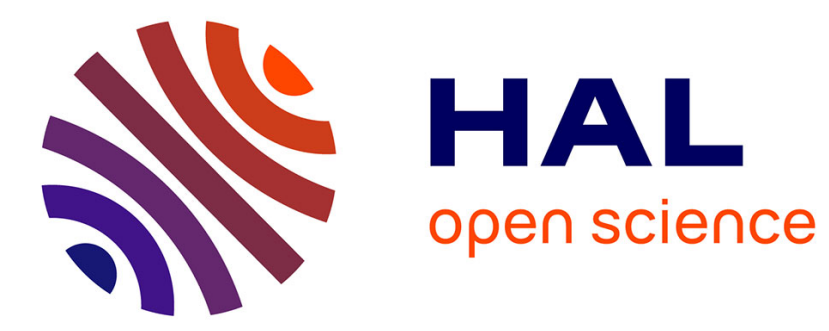

\title{
Multi-diagnostic soot measurements in a laminar diffusion flame to assess the ISF database consistency
}

Benedetta Franzelli, M. Roussillo, P. Scouflaire, J. Bonnety, R. Jalain, T.

Dormieux, S. Candel, G. Legros

\section{- To cite this version:}

Benedetta Franzelli, M. Roussillo, P. Scouflaire, J. Bonnety, R. Jalain, et al.. Multi-diagnostic soot measurements in a laminar diffusion flame to assess the ISF database consistency. Proceedings of the Combustion Institute, 2018, 10.1016/j.proci.2018.05.062 . hal-01856558

\section{HAL Id: hal-01856558 \\ https://hal.science/hal-01856558}

Submitted on 12 Aug 2018

HAL is a multi-disciplinary open access archive for the deposit and dissemination of scientific research documents, whether they are published or not. The documents may come from teaching and research institutions in France or abroad, or from public or private research centers.
L'archive ouverte pluridisciplinaire HAL, est destinée au dépôt et à la diffusion de documents scientifiques de niveau recherche, publiés ou non, émanant des établissements d'enseignement et de recherche français ou étrangers, des laboratoires publics ou privés. 


\title{
Multi-diagnostic soot measurements in a laminar diffusion flame to assess the ISF database consistency
}

\author{
B. Franzelli ${ }^{\mathrm{a}, *}$, M. Roussillo ${ }^{\mathrm{a}, \mathrm{b}}$, P. Scouflaire ${ }^{\mathrm{a}}$, J. Bonnety ${ }^{\mathrm{c}}$, R. Jalain ${ }^{\mathrm{c}}$, \\ T. Dormieux ${ }^{\mathrm{a}}$, S. Candel ${ }^{\mathrm{a}}$, G. Legros ${ }^{\mathrm{c}}$ \\ ${ }^{a}$ EM2C, CNRS, CentraleSupélec, Université Paris-Saclay, 91190 Gif-sur-Yvette, France \\ ${ }^{\mathrm{b}}$ Air Liquide, R\&D Paris Saclay, 1 Chemin de la porte des Loges, 78354 Jouy-en-Josas, France \\ ${ }^{\text {c}}$ Sorbonne Université, Centre National de la Recherche Scientifique, UMR 7190, Institut Jean Le \\ Rond d'Alembert, F-75005 Paris, France
}

\begin{abstract}
Control of soot emission raises fundamental issues and has important practical implications requiring a full understanding of soot production and oxidation processes. The research reported in the present paper intends to contribute to the studies carried out within the frame of the International Sooting Flame workshop (ISF) on laminar sooting flames. The objective is to identify and quantify sources of experimental errors and to extend the existing database for the Yale laminar diffusion burner flame. This will especially enable more comprehensive comparisons among different experimental techniques and numerical simulations. To this end, a combined use of Modulated Absorption/Emission (MAE) and Laser Induced Incandescence (LII) techniques is presented in this work. Results are compared with already existing experimental data in terms of soot volume fraction, soot temperature and primary particle size distribution, highlighting the high variability of the experimental data depending on the measurement techniques as
\end{abstract}

\footnotetext{
* Corresponding author

Email address: benedetta.franzelli@cnrs .fr (B. Franzelli)
} 
well as the underlying assumptions and post-processing methods. These complementary original data may serve to guide the validation of numerical modeling in this configuration.

Keywords: soot, MAE, time-resolved LII, primary particle size distribution, polydispersion 


\section{Introduction}

Soot is a major issue due to its adverse effects on human health and climate $[1,2]$. A better understanding of soot formation and oxidation, defining the total net production, is needed in order to control these emissions. This question is examined in the framework of the ISF workshop [3] by combining experimental and numerical investigations on a wide range of sooting flame configurations. Among them, the Yale Diffusion Burner (YDB [4]) allows fundamental investigations of soot production in laminar axisymmetric diffusion flames at atmospheric pressure for different dilutions of the inner fuel stream, i.e. $32 \%, 40 \%, 60 \%$, and $80 \%$ of ethylene diluted with nitrogen (by volume). The experimental setup simplicity enables the combination of different measurements to better understand the links between flame's temperature, gaseous quantities, flow field, and soot particles. A comprehensive experimental database already exists for this burner, including temperature measurements via pyrometry [5] and two-line atomic fluorescence [6], laser induced incandescence (LII) [7] and pyrometry [5] for soot volume fraction $f_{v}$, Particle Imaging Velocimetry (PIV) [8] for measurements of the velocity field; transmission electron microscope (TEM) measurements [9] to determine the primary particle size distribution (PPSD) and Time-Resolved LII (TR-LII[6]) to measure mean primary particle diameter. Unfortunately, these techniques have not been systematically applied to the four dilution cases so that the experimental database is still incomplete.

This configuration is also widely used to validate soot models for laminar configurations $[7,10]$. However, the validation procedure requires a consistent database and estimated uncertainties, reduced to the lowest possible level by comparing different diagnostics. 
Following this line of thought, the present investigation exploits for the first time a combination of LII [11] and Modulated Absorption/Emission (MAE) [12, 13] techniques, and proposes a comparison with existing results to enhance the database on soot volume fraction, temperature and primary particle size distribution. New temperature measurements obtained from pyrometry with a digital camera [5] complete this database.

The present paper begins with a brief description of the experimental setup (Sec. 2). Optical diagnostics used to measure $f_{v}$ and soot temperature are introduced in Sec. 3 and results for the $80 \%$ case are presented. Finally, the TR-LII technique is employed in Sec. 4 to access the PPSD and its response to dilution.

\section{Experimental setup}

The YDB, originally designed at Yale University [4], consists of an inner fuel injection tube surrounded by a co-flow of air [7]. Fuel and oxidizer flows are set to guarantee an average cold-flow velocity of $v_{f}=35 \mathrm{~cm} / \mathrm{s}$. Bronkhorst El-Flow electronic flow controllers are used with a calculated uncertainty of $\pm 0.3 \%$ FS (Full Scale) and regulation loop accuracy of $\pm 0.1 \%$ FS.

Using a high grade caliper, it was found that the central fuel injection tube has an inner diameter of $d_{f}=3.9 \mathrm{~mm}$, that slightly differs from the nominal 4.0 $\mathrm{mm}$ value of the reference burner. This induces a difference between the nominal and the real flow rates (calculated from $v_{f}$ and $d_{f}$ values) that has a measurable impact on the flame length. As an example, a variation of $4 \%$ of the flow rate induces an increase of nearly $6 \mathrm{~mm}$ in flame length for the $80 \%$ case. Such a sensitivity may explain discrepancies in the flame length observed in some previous measurements [5-7]. The outer diameter of the air co-flow has been reduced to $50 \mathrm{~mm}$ to enhance the stability of steady flames via an additional outer aluminum 
ring on top of the burner, thus alienating the flickering of the flame. It has been verified that such modifications do not affect the mean flame length and its structure. However, a small fluctuation of the flame luminosity of approximately $4 \%$ is still observed for the longest flame (80\%).

To improve results accuracy, MAE and LII setups have been optimized so that different laser and filters wavelengths are used for the two techniques. The LII measurements of the 2-D soot volume fraction field are carried out with a Nd:YAG laser $(1064 \mathrm{~nm})$ focused in the form of a sheet on the burner axis (convergent lens $\mathrm{f}=+1000$, cylindric lens $\mathrm{f}=-50$ ). The sheet is $10 \mathrm{~cm}$ wide and $0.35 \mathrm{~mm}$ thick at the focal point. Only its inner part $(7 \mathrm{~cm})$ is considered to get a nearly uniform laser fluence approximately equal to $0.45 \mathrm{~J} / \mathrm{cm}^{2}$ (shot duration $\approx 9 \mathrm{~ns}$ ), which corresponds to the plateau region of the LII signal [14]. This value guarantees to minimize the effect of laser energy variations even if it can lead to sublimation of the smallest particles, which is here assumed as negligible compared to the total $f_{v}$. At a wavelength of $1064 \mathrm{~nm}$, fluorescence from precursors is avoided and there is no need to discriminate between fluorescence and incandescence signals. Therefore, the camera gate delay $t_{0}$ is set to zero [15] with an exposure time of $25 \mathrm{~ns}$ to minimize the overestimation of the contribution of the biggest soot particles to the total $f_{v}$ [14]. In addition, the signal is collected at six delay times $\left(t_{i}=50,75,100,200,400,600 \mathrm{~ns}\right)$ to retrieve PPSD information based on TR-LII measurements [16]. The LII signal is recorded with an intensified CCD camera (Princeton, PI-MAX 3, $1024 \times 1024$ pixels) equipped with a lens (Nikkor $50 \mathrm{~mm} \mathrm{f} / 2$ ) and a $50 \mathrm{~nm}$ bandpass filter centered at $425 \mathrm{~nm}$ (ASAHI SPECTRA YBPA425). This filter reduces parasitic $\mathrm{C}_{2}$ Swan band emission and flame luminosity [17]. 
The two-color MAE (2C-MAE) experiments use two different $100 \mathrm{~mW}( \pm 0.5$ $\mathrm{mW})$ Spectra-Physics Excelsior CW Lasers operating at $645 \mathrm{~nm}(-5 /+7 \mathrm{~nm})$ and $785 \mathrm{~nm}(-5 /+5 \mathrm{~nm})$. MAE signals are acquired with a CMOS camera $(1312 \times 1312$ pixels) equipped with filters centered at $645 \mathrm{~nm}( \pm 2 \mathrm{~nm})$ and $785 \mathrm{~nm}( \pm 3 \mathrm{~nm})$. Working at $645 \mathrm{~nm}$ for MAE measurements of $f_{v}$ allows to optimize the absorption signal compared to the scattering by soot particles.

A digital Nikon D7000 camera, placed at $3 \mathrm{~m}$ from the flame to guarantee a difference of the maximum angle between the light rays of less than 2 degrees, is used to capture flame luminosity using the lowest possible value for the ISO number and the exposure time (120 and 1/8000 s, respectively). To enhance the signal-to-noise ratio, all data are averaged over 150 images.

\section{Measurements of soot volume fraction and soot temperature combining MAE and LII}

In this work, a combined use of MAE and LII techniques is proposed for the first time. On the one hand, the MAE technique is used to calibrate the LII signal, to measure temperature fields and to obtain information on the local spectral absorption field, which allows for the correction of the pyrometry signals for soot self-absorption along the line-of-sight. On the other hand, LII measurements provide information on both $f_{v}$ and PPSD.

\subsection{Soot volume fraction}

The soot volume fraction field is here retrieved using two different techniques, MAE and LII. The MAE technique [12] gives access to the local spectral absorption field $\kappa_{\lambda}$ by comparing the flame luminosity with and without a collimated 
laser crossing the flame. The $f_{v}$ field is extracted from information at one wavelength $\left(\lambda_{1}=645 \mathrm{~nm}\right)$. The local spectral absorption field $\kappa_{\lambda}$ is then used to obtain the soot volume fraction field using the Mie theory: $f_{v}=\lambda \kappa_{\lambda} /\left(6 \pi E\left(m_{\lambda}\right)\right)$, where $E\left(m_{\lambda}\right)$ is a function of the complex refractive index $m_{\lambda}$ of soot, varying with the detection wavelength $\lambda$. Since $f_{v}$ is proportional to $1 / E\left(m_{\lambda}\right)$, the errors in characterizing $E\left(m_{\lambda}\right)$ directly induce uncertainties in the soot volume fraction value. The experimental measurements of $E\left(m_{\lambda}\right)$ present a degree of variability, as they depend on the fuel considered, on soot maturity $[9,18]$ and on $\lambda$. In this work, the value $E\left(m_{\lambda}\right)$ is adapted from that reported by Kempena et al. [9] and Coderre et al. [19] by applying the MAE to a Santoro burner [20] and comparing with previous data. The value $E\left(m_{\lambda=645 \mathrm{~nm}}\right)=0.38$ gives consistent $f_{v}$ results in this reference flame but one has to keep in mind that the variability of $E\left(m_{\lambda}\right)$ may induce an error in $f_{v}$ of up to a factor two. In addition, results near the flame centerline may be affected by the in-house deconvolution process employed to reconstruct 2D-fields from the information integrated on the line-of-sight [12]. The error, estimated at $2.5 \%$ for the Santoro flame, may be reduced by using the Tikhonov regularization procedure [21] but it is considered as negligible compared to the other detected uncertainties.

In the LII technique [22], the soot volume fraction is proportional to the measured signal: $I^{\mathrm{LII}}=C_{\mathrm{cal}} f_{v}$, which is here calibrated with the MAE results $f_{v}^{\mathrm{MAE}}$. The LII signal is subject to various uncertainties. First, it can be affected by laser light absorption. In the present configuration the laser sheet traverses the flame from left to right, so that in this axisymmetric flame, this issue can be easily overcome by only considering data gathered on the left side of the flame. Second, the LII signal can be affected by the calibration procedure. Here, the calibration constant 
$C_{\text {cal }}$ is calculated by averaging the first $p$ higher pixel values of MAE and LII signals, located in the left flame wing, where results are less affected by the MAE deconvolution procedure and soot absorption. It has been observed that the calibration constant varies by up to $10 \%$ depending on the numbers $p$ of maximum values considered (here $p=100$ ). Third, the LII signal collected by the camera is affected by absorption due to the presence of soot in the detection pathway $[21,23,24]$. The effect of self-absorption on LII results in this flame is quantified by retrieving the emitted LII signal with an iterative procedure, described in the supplementary materials, making use of the detected signal and the postprocessing approach developed for the MAE. By comparing emitted and detected signals, it is found that the self-absorption is highest in the central region of the flame. A maximum attenuation of $5 \%$ on $f_{v}$ is observed for the most sooting case $(80 \%)$.

To conclude, error bars for results presented in Sec. 3.3 can be deduced as the result of all the uncertainties discussed in this section.

\subsection{Soot temperature}

New measurements of soot temperature are also provided. On the one hand, the 2C-MAE technique [12] allows to map soot temperature from information on measured fields of local spectral emission rate and local absorption coefficient $\kappa_{\lambda}$ at two wavelengths $\left(\lambda_{1}=645 \mathrm{~nm}\right.$ and $\left.\lambda_{2}=785 \mathrm{~nm}\right)$. For the temperature measurement itself, this technique needs no calibration or modeling to correlate $f_{v}$ and $k_{\lambda}$, avoiding the issue of the large discrepancies in the wavelength-dependent soot refractive index discussed in the previous section.

On the other hand, the frames required by the $2 \mathrm{C}-\mathrm{MAE}$ procedure are processed by following the methodology associated with the 2C-pyrometry tech- 

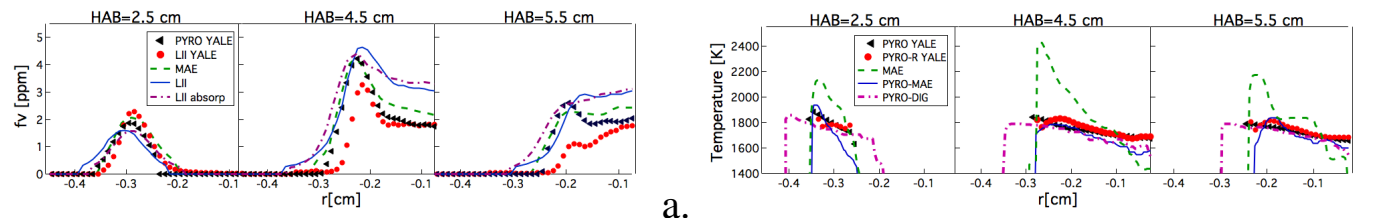

b.

Figure 1: Soot volume fraction (a) and temperature (b) at three heights above the burner for the $80 \%$ case. Comparison of different measurement techniques for $f_{v}$ (LII from Yale [7], pyrometry from Yale [5], new LII and MAE results) and temperature (pyrometry from Yale with and without constant properties [7], new pyrometry and MAE results).

nique [5]. In contrast with the regular 2C-pyrometry technique, this procedure (described in the supplementary materials) inherently accounts for the soot selfabsorption along the line-of-sight [25-28]. Compared to the MAE temperature, pyrometry results depend on the model retained for the spectral dependence of $m_{\lambda}$. Here, the model assessed by Chang and Charalampopulos [29] and usually prescribed for ethylene flames [26] is retained.

Additional temperature fields are obtained from pyrometry using a digital camera [5]. Results from the three color channels (.NEF format) are post-processed using a look-up table built using the camera spectral sensitivity presented in [30] and assuming that the soot emissivity varies with $\lambda^{-1.38}$. It has been observed that a $5 \%$ variation of the exponent's value leads to a temperature variation of about 60 K.

\subsection{Comparison with data from literature}

The objective is now to validate the present measurements and to compare results with other techniques. The most sooting case $(80 \%)$ is considered in this section. Profiles of $f_{v}$ from MAE and LII are presented in Fig. 1a at the three heights above burner (HAB) presented in Fig. 2. The correspondent 2D fields 
are provided as supplementary material. To our knowledge, this is the first time that a comparison between MAE and LII techniques is provided. It shows a good agreement between MAE and LII in the flame wings since this region corresponds to the zone used to perform the calibration. Close to the flame centerline, differences between MAE and LII signals appear where the deconvolution process used by the MAE technique is less accurate. LII signals corrected by auto-absorption (LIIabsorp) are also presented. Only small discrepancies are detected among LII and LIIabsorp signals, so that auto-absorption contribution can be considered as negligible for this configuration as expected due to the low optical thickness of the flame.

Data from previous studies performed at Yale with LII [7] are also plotted in Fig. 1a for comparison. The new MAE and LII results are greater by about $20 \%$ than LII data from the literature but they present the same general aspect with a high level of soot in the lateral region of the flame. The observed differences between the present data and those from the literature are within the error uncertainties discussed at the previous section, but they may also be due to additional differences in the LII experimental setup: the choice of the laser wavelength $(\lambda=532$ $\mathrm{nm})$ and the resulting choice for $\mathrm{E}(\mathrm{m})$, which in the previous studies was higher $\left(E\left(m_{\lambda=532 \mathrm{~nm}}\right)=0.45\right)$, the filter used for LII and the experimental technique to obtain the calibration.

Literature $f_{v}$ data from pyrometry [5] are also plotted in Fig. 1a. They show a good agreement with the present database in the flame wings, but are smaller in the centerline compared to the LII results. This is possibly due to the deconvolution procedure as discussed for the MAE technique.

Temperature fields obtained with MAE and pyrometry techniques are compared in 
Fig. $1 \mathrm{~b}$ to the pyrometry measurements with and without constant properties (RPYRO and PYRO [5], respectively) obtained at Yale. Similar results are deduced with the four pyrometry techniques in the flame wings, with a maximum temperature discrepancy of less than $100 \mathrm{~K}$. It can be noticed that pyrometry results obtained here with a digital camera (PYRO-DIG) are detected for a wider radial region. However, it should be noticed that also the new LII results extends to a wider radial position, possibly explaining the difference with previous pyrometry data. On the contrary, pyrometry from MAE fields needs a sufficiently high soot concentration to obtain information on $\kappa_{\lambda}$, reducing the region where the signal is detectable.

Temperature deduced from MAE in the flame wing is much higher than that obtained from pyrometry, whereas results are closer in the flame middle. This may highlight the effect of the model used to represent the spectral dependence of $m_{\lambda}$ in the pyrometry procedure. However, a simulation of a $1 \mathrm{D}$ counterflow diffusion flame representative of the investigated flame (ambient temperature, atmospheric pressure, strain rate of $1 \mathrm{~s}^{-1}, 80 \%$ ethylene diluted with $\mathrm{N}_{2}$ ) has been performed using the models presented in [31] and shows that the maximum temperature does not exceed $2150 \mathrm{~K}$. Therefore, numerical results seem to indicate that the high values detected in the wings with the MAE may be un-physical. In this regard, it is worth reminding that the accuracy of the MAE temperature measurements depends on the optical thickness along the line-of-sight because inferring the temperature first requires the measurement of the absorption coefficient field [12]. In the YDB flame, the optical thickness is significantly lower than that of the Santoro burner, the MAE technique having been validated with this burner configuration [12]. The lower optical thickness of the YDB flame and the sharp temperature 
gradients in the flame wings possibly alter the $\kappa_{\lambda}$ resolution and, consequently, results accuracy.

In conclusion, measurements of $f_{v}$ and temperature feature a significant variability that needs to be quantified by comparing different experimental techniques and to be accounted for during the validation process of numerical models.

\section{Measurements of primary particle sizes}

\subsection{Time-resolved LII technique}

The evolution of the LII signal decay contains information on the primary particle size distribution (PPSD) [32] so that size data may be extracted from timeresolved 2D LII signals, based on a regression method relying on modeled LII signal. An example of TR-LII images $I_{i}=I\left(t_{i}\right)$, normalized by the signal $I_{0}$ at $t_{0}=0 \mathrm{~ns}$, is displayed in Fig. 2 for the $80 \%$ case. The decay time being longer for larger primary particles, it can be deduced that the PPSD is spatially variable. In particular, big particles are expected to be found in the flame outer region. Among the different techniques, the one proposed by Dankers and Leipertz [33] and extensively validated by Chen et al. [16] on a Santoro flame is here retained.

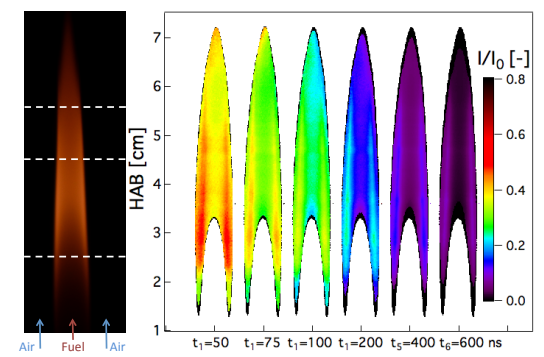

Figure 2: TR-LII images captured at six delay times $t_{i}$ and normalized by the signal $I_{0}$ at $t_{0}=0 \mathrm{~ns}$. 


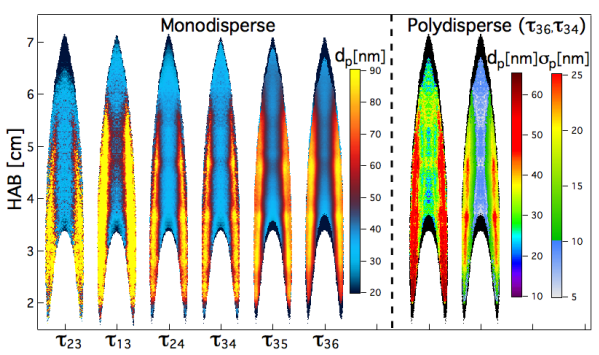

Figure 3: Fields of primary particle size distribution for $80 \%$ case. Left: mean diameter under monodisperse assumption for six decay times. Right: mean diameter and standard deviation for a log-normal polydisperse population based on delay times $\tau_{34}$ and $\tau_{36}$.

The LII signal is approximated by an exponential decay function: $I^{\mathrm{LII}} \propto \exp (-t / \tau)$, where $\tau$ is the exponential decay time, which can be estimated as: $\tau_{i j}=\left(t_{i}-t_{j}\right) /\left(\ln I_{j}-\ln I_{i}\right)$. Information on PPSD is obtained for each spatial position by comparing experimental decay times $\tau_{i j}^{\text {exp }}$ to a look-up table containing modeled decay times $\tau_{i j}^{\text {mod }}$. Thus, results on PPSD, such as the mean primary particle diameter $d_{p}$, will depend on the models used to build the look-up table and to perform the non-linear regression. By assuming a monodisperse population, $d_{p}$ can be obtained by minimizing: $\mathcal{F}\left(d_{p}\right)=\left[\tau^{\exp }-\tau^{\bmod }\left(d_{p}\right)\right]^{2}$, where $\tau^{\bmod }\left(d_{p}\right)$ is here calculated by performing simulations of LII decay signal for a single particle of diameter $d_{p}$ using the LIISim-Web tools [34] developed by Hofmann et al. [35]. Eighteen diameters from $d_{p}=4 \mathrm{~nm}$ to $d_{p}=100 \mathrm{~nm}$ are considered to build the look-up table, imposing a gaseous temperature $T_{g}=1700 \mathrm{~K}$. Details on the modeling are described in [35] and simulation parameters are provided in the supplementary material. Results in terms of mean primary particle diameter for the $80 \%$ case are illustrated in Fig. 3 for $\operatorname{six} \tau_{i j}$. They confirm the qualitative trend deduced from Fig. 2, since the largest primary particles, with a diameter of about $90 \mathrm{~nm}$, are located in the 
flame wings whereas the presence of smaller primary particles (with $d_{p} \approx 40 \mathrm{~nm}$ ) characterizes the central region. The quality of the results strongly depends on the decay time used to perform the minimization, i.e. on the retained gate delays. In particular, for small gating delays results are quite noisy. In [16], it is indicated that gating delays should be sufficient to avoid the effects of the vaporization period. For the fluence considered in the present experiments $\left(0.45 \mathrm{~J} / \mathrm{cm}^{2}\right)$, vaporization is not negligible at the beginning of the simulated LII signal and up to $t_{3}=100 \mathrm{~ns}$, explaining the tendencies observed in Fig. 3. However, it has been verified by performing LIISim-Web simulations with a lower $0.1 \mathrm{~J} / \mathrm{cm}^{2}$ that even in case of negligible vaporization, results are highly dependent on the choice of $\tau_{i j}$ when small gating delays are considered (not shown). In contrast, when the gating delays are sufficient, results on $d_{p}$ become consistent. It is then important to choose detection gates that are sufficiently delayed while preserving a good signal-to-noise ratio. This implies that information will be lost in the region characterized by the smallest particles, that appears as black zones in Figs. 2 and 3. The proper choice depends on the flame under investigation and on its particle size distribution.

To take into account polydispersion, one often presumes a log-normal probability density function featuring two parameters $d_{\mathrm{cmd}}$ and $\sigma$ :

$$
f(d)=\frac{1}{\sqrt{2 \pi} d \ln \sigma} \exp \left[-\frac{\left(\ln d-\ln d_{\mathrm{cmd}}\right)^{2}}{2(\ln \sigma)^{2}}\right] .
$$

The mean primary particle diameter $d_{p}=\exp \left(\ln d_{\mathrm{cmd}}+(\ln \sigma)^{2} / 2\right)$ and the variance $\sigma_{p}^{2}=\left(\exp \left((\ln \sigma)^{2}\right)-1\right) \exp \left(2 \ln d_{\mathrm{cmd}}+(\ln \sigma)^{2}\right)$ can be obtained by minimizing: $\mathcal{F}\left(d_{\mathrm{cmd}}, \sigma\right)=\left[\tau^{\exp }-\tau^{\bmod }\left(d_{\mathrm{cmd}}, \sigma\right)\right]^{2}$. A second look-up table is then 
build with the LIISim-Web tool using the same parameters as in the monodisperse simulation but considering polydisperse soot particles. Six values of $d_{\mathrm{cmd}}$ are considered between 10 and $60 \mathrm{~nm}$ and $\sigma$ varies from 1.1 and 1.7 with an interval of 0.1. Results based on the polydispersed population are plotted in the right side of Fig. 3. They qualitatively reproduce the same spatial distribution of $d_{p}$ found in the monodisperse case with the smallest and biggest particles located on flame centerline and wings, respectively. However, compared to the monodisperse calculation, the diameter for the biggest particles is about $60 \mathrm{~nm}$, a value smaller than that of the monodisperse results. The centerline primary particle diameter is approximately of $30 \mathrm{~nm}$, close to the monodisperse value. This seems to indicate that a quasi-monodisperse population of primary particles characterizes the centerline, whereas a polydispersed population is observed in the flame wings. This is confirmed by standard deviation results, that are quite small on the centerline and increase in the flame wings. The present results show trends that are similar to those of Chen et al. [16] obtained for the Santoro burner, confirming the present interpretation. However, it is worth noting that the present results depend on the model used to create the look-up table. For example, a constant gaseous temperature is here assumed for simplicity, even if temperature results have been presented at the previous section. The impact of this assumption has been estimated in [16] to be about $4 \%$ in decay times. In addition, the role of the post-processing procedure and other model assumptions, such as considering single particles instead of aggregates, i.e. the shielding effect is neglected, is estimated in [16] to introduce errors of $30 \%$ in $d_{p}$ and $5 \%$ in $\sigma_{p}$. More generally, modeling of LII signal is known to be characterized by a large variability, especially at high fluence [36]. It is therefore important to provide access not only to the final results 


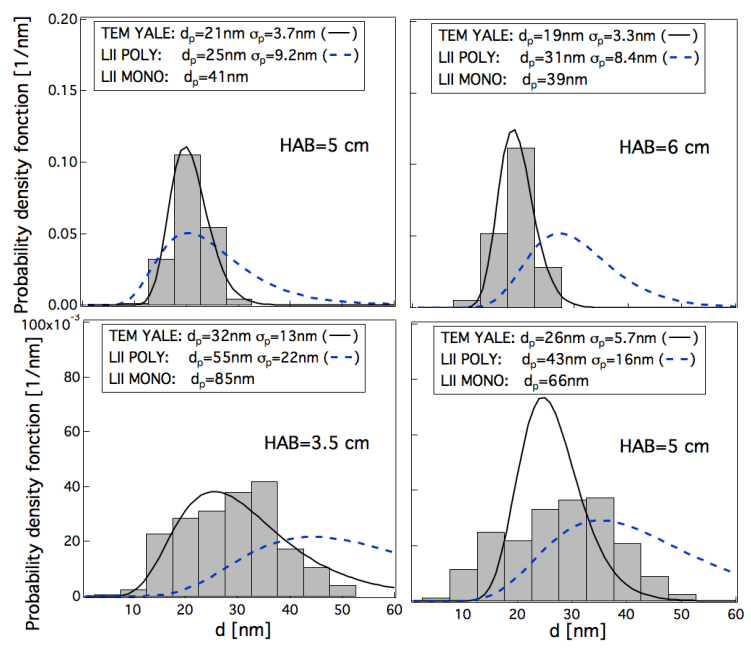

Figure 4: Bar graphs of $d_{p}$ along the centerline (top) and wing (bottom) at two HAB from TEM measurements for $80 \%$ case [9]. The solid lines are lognormal fittings to the sampled TEM data and the dashed lines are from the present TR-LII measurement.

in terms of $d_{p}$ and $\sigma_{p}$ but also to TR-LII signals like those shown in Fig. 2 and to LII simulated signals used to create the look-up table (provided as supplementary material), which could be used to perform a more pertinent comparisons among different experimental measurements and numerical models.

\subsection{Comparison with TEM measurements}

TEM measurements performed at Yale are available at different locations for the $80 \%$ case [9], which are here compared to the TR-LII data. Results from TEM (vertical bars) are presented in Fig. 4 for four positions together with the lognormal fittings to the sampled TEM (continous) and to the LII (dashed) data obtained in the previous section using a polydisperse population. The values of $d_{p}$ using a monodisperse assumption are also added to Fig. 4. The exact radial position for TEM measurement in the flame wings not being provided, the LII data has been 


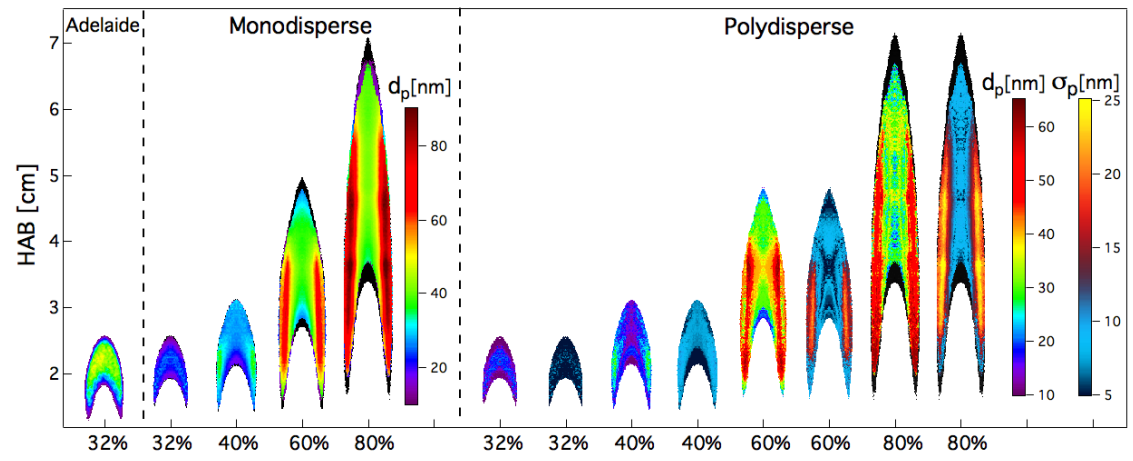

Figure 5: 2D fields of PPSD for four dilutions. Left: $d_{p}$ from Adelaide TR-LII measurements [6]. Middle: $d_{p}$ under monodisperse assumption $\left(\tau_{13}\right.$ for $32 \%, \tau_{34}$ for $40 \%, \tau_{35}$ for $60 \%, \tau_{36}$ for $\left.80 \%\right)$. Right: $d_{p}$ and $\sigma$ for a log-normal polydisperse population $\left(\left(\tau_{13}, \tau_{23}\right)\right.$ for $32 \%,\left(\tau_{24}, \tau_{34}\right)$ for $40 \%,\left(\tau_{34}, \tau_{35}\right)$ for $60 \%$ and $\left(\tau_{34}, \tau_{36}\right)$ for $80 \%)$.

extracted at the location of maximum $d_{p}$. In general, for all spatial locations, the LII particle size population is shifted towards larger diameters compared to TEM distributions. Concerning the centerline (top), LII results slightly overestimate $d_{p}$ and $\sigma_{p}$ compared to TEM measurements when using a polydisperse assumption. With the monodisperse model, $d_{p}$ is strongly overestimated. In the TEM results, $\sigma_{p}$ is nearly constant for HABs of 5 to $6 \mathrm{~cm}$. This tendency is correctly reproduced by the LII measurements. As expected, TEM results in the flame wings show higher values of $d_{p}$ and $\sigma_{p}$ compared to the centerline. Even if LII results retrieve the same qualitative behavior, $d_{p}$ values are strongly overestimated in the wings when using a polydisperse assumption and even higher discrepancies are found for the monodisperse case. Uncertainties on the radial position of TEM measurements may partially explain such discrepancies, since it has been observed in the LII results that a variation of $0.5 \mathrm{~mm}$ in the radial position decreases the $d_{p}$ value of about $30 \%$. In addition, TEM measurements present in 
the flame wings a population that cannot be represented with a log-normal distribution, so that the assumption underlying the polydisperse LII model might not be valid. As already discussed, neglecting the shielding effect can also partially explain the observed differences. However, it should be noticed that these results present the same trend for TEM-LII comparison observed for state-of-the-art measurements on the Santoro burner $[9,16]$. In general, such a comparison may be critical since LII and TEM techniques do not strictly measure the same quantity (effective and measured diameters, respectively).

\subsection{Dilution effects on PPSD}

The TR-LII technique is now applied to investigate flames at four dilutions with the monodisperse and log-normal assumptions. Results are displayed in Fig. 5. To our knowledge, this is the first time that the effect of dilution on primary particle size distribution is investigated on the YDB flame. First, one observes that the spatial distribution of $d_{p}$, which is qualitatively the same for monodisperse and polydisperse assumptions, is correlated with the $f_{v}$ fields (shown in the supplementary materials). A nearly homogeneous value of $d_{p}$ is identified for $32 \%$ and $40 \%$ cases, whereas big primary particles are found in the flame wings for $60 \%$ and $80 \%$ cases. Small values of $\sigma_{p}$ are found for the $30 \%$ and $40 \%$ cases so that the primary particle distributions can be considered as quasi-monodisperse. Therefore, $d_{p}$ results are similar when assuming monodisperse or polydisperse populations in these two flames. In contrast, high values of $\sigma_{p}$ are observed in the wings of $60 \%$ and $80 \%$ flames, where a polydisperse population is expected and confirmed by the differences in $d_{p}$ corresponding to monodisperse and polydisperse results. One may generally conclude that by increasing the presence of fuel in the diluted mixture, higher values of $f_{v}$ are observed in the flame wings, where 
the soot population of primary particles is also more polydispersed and shifted toward larger diameters. This is probably the results of two effects affecting chemical and collisional soot processes: the increase of precursors concentrations, since reactive species concentrations increase, and the change in the flame temperature as a consequence of the streams' physical properties variation [37, 38]. It should be noticed that dilution may also affect particle optical properties, introducing an additional uncertainties to soot volume fraction measurements. Their quantification is out of the scope of this paper and they are here considered small compared to the global uncertainty on $\mathrm{E}(\mathrm{m})$.

Finally results for the $32 \%$ case (Fig. 5) are compared with the $d_{p}$ field measured with a TR-LII technique at Adelaide using a mono-disperse assumption [6]. While a nearly homogeneous spatial distribution of $d_{p}$ is also observed in the Adelaide measurement, it should be noticed that $d_{p}$ has been estimated to be close to $50 \mathrm{~nm}$, whereas in the present measurements $d_{p}$ is less than $30 \mathrm{~nm}$ with both monodisperse and polydisperse distributions. At this point, it is not possible to identify the source of such discrepancies, which may be due to differences in measurements, processing tools or models used to calculate the look-up table associated with the LII signal. However, on the basis of TEM results for the $80 \%$ case (showing that only a small number of particles exceeds $50 \mathrm{~nm}$ ), a mean $d_{p}$ value of $50 \mathrm{~nm}$ is quite unlikely for the $32 \%$ flame. In general, it can be concluded that PPSD results present an high variability and that it is essential to include data from as many measurement techniques as possible to create a reliable experimental database for modeling validation. 


\section{Conclusion}

The objective of the present investigation is to provide new measurements for the YDB flame in order to obtain a reliable and comprehensive experimental database that can be used to validate numerical models for soot production. This is done by combining for the first time LII and MAE techniques. In particular, MAE information is used to calibrate the LII signal for $f_{v}$, to provide new temperature measurements and to account for soot self-absorption on pyrometry signals. Time-resolved LII provides information on PPSD in terms of mean and standard deviation of the primary particle diameter. The study indicates that: (1) A qualitative agreement is observed among the different techniques for $f_{v}$ and temperature measurements but quantitative differences are detected; (2) The primary particle size $d_{p}$ correlates with the $f_{v}$ field and that by increasing the presence of fuel in the diluted mixture the dispersion in PPSD increases; (3) When using a monodisperse assumption, the $d_{p}$ distribution is qualitatively retrieved but its value is largely overestimated; (4) A high variability in PPSD is observed depending on the diagnostics and post-processing methods. In general, the need of a cross comparison between multiple data has been evidenced to define a consistent database for sooting flames. For this, access to the measured fields should be provided together with the post-processed results and the modeled signals.

\section{Acknowledgments}

This work is supported by the Air Liquide, Ecole Centrale Paris and CNRS OXYTEC Chair and by the OXYTEC project (ANR-12-CHIN-0001) from l'Agence Nationale de la Recherche. 


\section{References}

[1] J. H. Seinfeld, Nature 391 (1998) 837-838.

[2] A. Seaton, L. Tran, R. Aitken, K. Donaldson, J. R. Soc. Interface (2009).

[3] International Sooting Flame (ISF) Workshop available at http://www.adelaide.edu.au/cet/isfworkshop/ (Updated 2016).

[4] Sooting Yale Coflow Diffusion Flames, available at http://guilford.eng.yale.edu/yalecoflowflames/ (2016).

[5] P. B. Kuhn, B. Ma, B. C. Connelly, M. D. Smooke, M. B. Long, Proc. Combus.Inst. 33 (2011) 743-750.

[6] K. K. Foo, Z. Sun, P. R. Medwell, Z. T. Alwahabi, B. B. Dally, G. J. Nathan, Combust. Flame 181 (2017) $270-282$.

[7] M. Smooke, M. Long, B. Connelly, M. Colket, R. Hall, Combust. Flame 143 (2005) 613-628.

[8] A. M. Schaffer, Ph.D. thesis, Yale University, 2009.

[9] N. J. Kempema, B. Ma, M. B. Long, Appl. Phys. B 122 (2016) 1-13.

[10] A. Jocher, K. K. Foo, Z. Sun, B. Dally, H. Pitsch, Z. Alwahabi, G. Nathan, Proc. Combust. Inst. 36 (2017) 781âĂŞ788.

[11] B. C. Connelly, Ph.D. thesis, Yale University, 2009.

[12] G. Legros, Q. Wang, J. Bonnety, M. Kashif, C. Morin, J.-L. Consalvi, F. Liu, Combust. Flame 162 (2015) 2705-2719. 
[13] M. Kashif, J. Bonnety, P. Guibert, C. Morin, G. Legros, Opt. Express 20 (2012) 28742-28751.

[14] P. Desgroux, X. Mercier, K. A. Thomson, Proc. Combus.Inst. 34 (2013) 1713 -1738 .

[15] C. S. Moreau, E. Therssen, X. Mercier, J. F. Pauwels, P. Desgroux, Appl. Phys. B 78 (2004) 485-492.

[16] L. Chen, J. Wu1, M. Yan, X. Wu, G. Grehan, K. Cen, Appl. Phys. B 123 (2017) 1-13.

[17] C. R. Shaddix, K. C. Smyth, Combust. Flame 107 (1996) 418 - 452.

[18] G. Cléon, T. Amodeo, A. Faccinetto, P. Desgroux, Appl. Phys. B 104 (2011) 297-305.

[19] A. R. Coderre, K. A. Thomson, D. R. Snelling, M. R. Johnson, Appl. Phys. B 104 (2011) 175-188.

[20] R. J. Santoro, T. T. Yeh, J. J. Horvath, H. G. Semerjian, Combust. Sci. Tech. 53 (1987) 89-115.

[21] F. Liu, K. A. Thomson, G. J. Smallwood, CEUR Workshop Proceedings 211 (2006) 27.

[22] G. S. S. W. H.A. Michelsen, C. Schulz, Prog. Energy. Comb. Sci. 51 (2015) $2-48$.

[23] F. Migliorini, S. De Iuliis, F. Cignoli, G. Zizak, Appl. Opt. 45 (2006) 77067711. 
[24] M. Y. Choi, K. A. Jensen, Combust. Flame 112 (1998) 485-491.

[25] R. J. Hall, P. A. Bonczyk, Appl. Opt. 29 (1990) 4590-4598.

[26] F. Liu, K. A. Thomson, G. J. Smallwood, Combust. Flame 160 (2013) 1693-1705.

[27] F. Cignoli, S. D. Iuliis, V. Manta, G. Zizak, Appl. Opt. 40 (2000) 5370-5378.

[28] G. S. F. Liu, K.A. Thomson, Appl. Phys. B 96 (2009) 671-682.

[29] H. Chang, T. T. Charalampopoulos, Proc. Roy. Soc. Lond. A 430 (1990) $577-591$.

[30] M. Saito, H. Iwabuchi, I. Murata, Applied Optics 55 (2016) 415-424.

[31] P. Rodrigues, B. Franzelli, R. Vicquelin, O. Gicquel, N. Darabiha, Proc. Combust. Inst. (2016) 1-8.

[32] H. Bladh, N. Olofsson, T. Mouton, J. Simonsson, X. Mercier, A. Faccinetto, P. Bengtsson, P. Desgroux, Proc. Combust. Inst. 35 (2015) 1843-1850.

[33] S. Dankers, A. Leipertz, Appl. Opt. 43 (2004) 3726-3731.

[34] LIISim-Web available at http://web.liisim.com/ (Updated 2016).

[35] M. Hofmann, B. Kock, C. Schulz, in: Proceedings of the European Combustion Meeting (2017), Kreta.

[36] H. Michelsen, F. Liu, B. Kock, H. Bladh, A. Boiarciuc, M. Charwath, T. Dreier, R. Hadef, M. Hofmann, J. Reimann, S. Will, P.-E. Bengtsson, H. Bockhorn, F. Foucher, K.-P. Geigle, C. Mounaïm-Rousselle, C. Schulz, R. Stirn, B. Tribalet, R. Suntz, Appl. Phys. B 87 (2007) 503-521. 
[37] D. Du, R. Axelbaum, C. Law, Symposium (International) on Combustion 23 (1991) $1501-1507$.

[38] F. Liu, H. Guo, G. J. Smallwood, O. L. Gulder, Combust. Flame 125 (2001) $778-787$. 